\title{
Pathways of Ammonia Metabolism in the Intact Functioning Kidney of the Dog*
}

\author{
William J. Stone $\dagger$ and Robert F. Pitts $\ddagger$ \\ (From the Department of Physiology, Cornell University Medical College, New York, N. Y.)
}

\begin{abstract}
Summary. Studies in which ${ }^{15} \mathrm{~N}$-labeled precursors of urinary ammonia were infused into the artery of an intact functioning kidney of an acidotic dog have led to the following conclusions: Preformed ammonia and ammonia derived from the amide nitrogen of plasma glutamine are added directly to urine without significant incorporation into amino acid intermediates of renal tissue. Thus, reductive amination of $\alpha$-ketoglutarate to form glutamate does not occur to an appreciable extent nor is there significant transfer of the amide nitrogen of glutamine to the corresponding keto acids to form glutamate, aspartate, alanine, or glycine. The enzyme system "glutaminase II" may participate to a significant extent in the metabolism of glutamine by forming aspartate and alanine by direct transamination of oxalacetate and pyruvate and liberating the amide nitrogen as ammonia. Renal alanine exists as a well mixed pool derived in roughly equal amounts from filtered and reabsorbed plasma alanine and newly synthesized alanine. The alanine pool of tubular cells does not equilibrate with the alanine of peritubular capillary blood. Transfer of the nitrogen of alanine to $\alpha$-ketoglutarate and subsequent oxidative deamination of the resulting glutamate can account for the ammonia formed from alanine. Glycine is not an important intermediate in renal nitrogen metabolism.
\end{abstract}

\section{Introduction}

If an ammonia-generating enzyme cannot be demonstrated in renal tissue in vitro [e.g., L-amino acid oxidase (1), urease (2)], one may reasonably infer that the reaction catalyzed by that enzyme does not contribute to renal production of ammonia in vivo. However, the mere presence of an ammonia-generating enzyme in renal tissue does not necessarily indicate that it contributes significantly to the production of ammonia by the intact functioning kidney. Certainly the activity of an enzyme under the highly artificial conditions of an in vitro assay cannot be related to its functional contribution in vivo with any confidence.

* Submitted for publication January 23, 1967 ; accepted March 15, 1967.

Aided by grants from the National Heart Institute of the National Institutes of Health (HE 00814, HTS 5264) and the Life Insurance Medical Research Fund.

$\dagger$ Fellow of the New York Heart Association.

$¥$ Address requests for reprints to Dr. Robert F. Pitts, Dept. of Physiology,, Cornell University Medical College, 1300 York Ave., New York, N. Y. 10021.
Enzymes known to be present in the kidney of the dog, and which are most likely to be involved in ammonia production, include glutaminase I, glutamine transaminase plus an omega amidase (glutaminase II), a variety of L-amino acid transferases, glycine oxidase (D-amino acid oxidase), and glutamate dehydrogenase. The latter is especially interesting, because in vitro studies have shown that the reaction which it catalyzes is reversible and that equilibrium greatly favors the synthesis of glutamate (3).

In the studies reported here, enzymatic pathways of ammonia production by the kidney in vivo were studied by the infusion of a ${ }^{15} \mathrm{~N}$-labeled precursor into one renal artery of an acidotic dog. Both kidneys were removed, and the distribution of isotopic nitrogen among a limited number of the free amino acids of kidney tissue and urinary ammonia was measured. The free tissue amino acids studied were limited to those which are stable and can be isolated in pure form in an amount sufficient to permit accurate analysis of content of label, 
namely glutamate, aspartate, glycine, and alanine. The number of precursors studied has been limited to those which we have synthesized in our laboratory, namely amide- and amino-labeled glutamines (4) and alanine (5). The number of experiments has been limited by the time involved in the chromatographic separation and purification of the tissue amino acids before ${ }^{15} \mathrm{~N}$ analysis.

We have observed in the acidotic dog that the ${ }^{15} \mathrm{~N}$ of ammonium chloride and of amide-labeled glutamine infused into the renal artery appears almost exclusively in the urinary ammonia and is not incorporated to any appreciable extent into the free glutamate, aspartate, alanine, and glycine of kidney tissue. Thus, the glutamate dehydrogenase system in vivo does not synthesize significant amounts of glutamate from $\alpha$-ketoglutarate and ammonia. Lacking labeled glutamate, ${ }^{15} \mathrm{~N}$ is not appreciably incorporated into other amino acids by transamination. Furthermore, as one might expect, the course of the amide nitrogen of glutamine to urinary ammonia is direct and does not involve an amino acid intermediate.

In contrast, the ${ }^{15} \mathrm{~N}$ of amino-labeled glutamine appears in the urinary ammonia and in all of the free amino acids of renal tissue that we have measured. The extent of labeling of both aspartate and alanine relative to glutamate suggests that the glutaminase II system may be significantly involved in the metabolism of glutamine. Similarly, when the ${ }^{15} \mathrm{~N}$ is administered as alanine, the label appears in the urinary ammonia and in all of the tissue amino acids studied. The distribution of label is consonant with the view that alanine nitrogen is transferred to glutamate and subsequently appears as urinary ammonia and as tissue aspartate and glycine. In general, little label appears in free tissue glycine no matter how the ${ }^{15} \mathrm{~N}$ is given.

\section{Methods}

Mongrel dogs of either sex weighing from 19 to $26 \mathrm{~kg}$ were fed $10 \mathrm{~g}$ of ammonium chloride mixed with their food on each of the 3 days before an experiment. After intravenous injection of not more than $1 \mathrm{ml}$ per $\mathrm{kg}$ of $3 \%$ sodium pentobarbital, a constant infusion containing $5 \mathrm{~g}$ creatinine, $22.5 \mathrm{~g} \mathrm{Na} \mathrm{SO}_{4} \cdot 10 \mathrm{H}_{2} \mathrm{O}$, and $5 \mathrm{ml}$ of $20 \%$ p-aminohippurate (PAH) per $\mathrm{L}$ was administered intravenously at $5 \mathrm{ml}$ per minute. An endotracheal tube was inserted to maintain the airway. A radio-opaque catheter was passed into the left renal vein under fluoroscopic visualization. A slow saline drip kept the catheter patent. Both ureters were exposed through a midline lower abdominal incision and catheterized to the level of the renal pelvis. An indwelling needle with tight stylet was placed in the right femoral artery. The left kidney was exposed retroperitoneally through a flank incision, and a curved 25-gauge needle connected to polyethylene tubing was introduced into the left renal artery near its origin from the aorta.

The ${ }^{15} \mathrm{~N}$ compound to be studied was dissolved in saline and infused into the left renal artery at a rate of approximately $10 \mu$ moles per minute $(0.97 \mathrm{ml}$ per minute) throughout the course of the experiment. After a 20minute equilibration period, urine was collected from each kidney for 15 minutes. Over a period of 2 minutes at the midpoint of the clearance period, time-integrated samples of arterial and renal venous blood were simultaneously withdrawn into heparinized syringes. At the end of the period, the two kidneys were rapidly removed, weighed, and separately homogenized in $600 \mathrm{ml}$ of saturated picric acid in paired Waring Blendors.

$\mathrm{PAH}$ was determined in whole blood and urine by the method of Pilkington, Binder, De Haas, and Pitts (6). Renal blood flow (RBF) was calculated by the equation of Wolf (7), and renal plasma flow (RPF) was derived from $\mathrm{RBF}$ and the measured arterial hematocrit. Creatinine in urine and plasma, ammonia in urine, arterial and renal venous plasma concentrations of amino acids, and ${ }^{15} \mathrm{~N}$ content of urinary ammonia were analyzed by methods previously described $(4,5,8)$. Creatinine clearance was taken as a measure of glomerular filtration rate (GFR). Urinary $\mathrm{pH}$ was measured by a RadiometerCopenhagen meter and a capillary glass electrode.

Kidney homogenates were centrifuged and filtered. Samples of $50 \mathrm{ml}$ and $500 \mathrm{ml}$ of each filtrate were separately treated according to the method of Tallan, Moore, and Stein (9). The smaller sample was flash evaporated at $30^{\circ} \mathrm{C}$ and analyzed for acidic and neutral amino acids on a Beckman model 120 automatic analyzer. The larger was similarly flash evaporated and used for chromatographic separation of glutamate, aspartate, alanine, and glycine. Glutamate and aspartate were removed and separated by chromatographing the amino acid mixture on Dowex $1 \times 8$ acetate, with $0.5 \mathrm{M}$ acetic acid as the eluent. The eluate was collected in $5-\mathrm{ml}$ fractions, spotted on filter paper, and sprayed with Ninhydrin to locate peaks. Glutamine survives this treatment, and more than $90 \%$ recoveries were obtained. Since no glutamate was formed, preformed kidney glutamate is not diluted with glutamate formed on the Dowex 1 acetate column from glutamine. The material emerging at column volume, including neutral and basic amino acids and ammonia, was flash evaporated, taken up in $25 \mathrm{ml}$ of $0.1 \mathrm{~N} \mathrm{HCl}$, and heated for 30 minutes in a boiling water bath to hydrolyze the glutamine. Although most of the glutamine is converted to pyrrolidone carboxylic acid, some glutamic acid is formed. This was removed by rechromatographing the residue on Dowex 1 acetate. The material that appeared at column volume was flash evaporated and chromatographed on Dowex 1 hydroxide, eluting with $50 \mathrm{ml}$ of distilled water to remove ammonia and basic 
amino acids. The neutral amino acids were next eluted with $0.5 \mathrm{M}$ acetic acid, flash evaporated, and chromatographed on Dowex $50 \times 4$ (hydrogen form), eluting with $1 \mathrm{~N} \mathrm{HCl}$ (10). Fractions were spotted on filter paper buffered with $4 \mathrm{M}$ sodium acetate and sprayed with Ninhydrin. Glycine and alanine peaks were identified, and the fractions corresponding to each were combined and flash evaporated. At this stage all amino acid samples were analyzed individually for quantity and purity by automatic column chromatography. Glutamate and aspartate were usually obtained in pure form and in amounts adequate for ${ }^{15} \mathrm{~N}$ analysis without dilution with unlabeled material. Glycine and alanine were usually impure, requiring repetition of chromatography one or several times on the resin appropriate to the impurity. When ultimately purified, the amounts of alanine and glycine obtained ( 30 to $40 \mu$ moles) were insufficient for ${ }^{15} \mathrm{~N}$ analysis. Therefore, $50 \mu$ moles of the identical unlabeled amino acid was added to each sample before conversion to ammonia by treatment with Ninhydrin (11). Subsequent aeration and trapping of ammonia and conversion to nitrogen gas for ${ }^{15} \mathrm{~N}$ analysis have been previously described (4).

\section{Results}

Two experiments were performed with each of four ${ }^{15} \mathrm{~N}$-labeled compounds: amide-labeled glutamine (94.9 atoms $\%{ }^{15} \mathrm{~N}$ excess), amino-labeled glutamine (91.4 atoms $\%{ }^{15} \mathrm{~N}$ excess), alanine (90.3 atoms $\%{ }^{15} \mathrm{~N}$ excess), and ammonium chloride (96.3 atoms $\%{ }^{15} \mathrm{~N}$ excess). Data obtained in a typical experiment are presented in Table $\mathrm{I}$. Glomerular filtration rates, urine $\mathrm{pH}$, weights, rates of ammonia excretion by the two kidneys, and concentrations of free amino acids in the tis- sue of the two kidneys were comparable in all eight experiments.

Net extractions of plasma amino acids observed in the eight experiments are shown in Table II. Since less than $1 \%$ of the filtered load of any amino acid was excreted in the urine, the net extraction of each amino acid, namely the arterial load in minus the venous load out, is essentially equal to rate of production or rate of utilization. Positive extraction is equated with utilization, negative extraction with production. The arterial load in is the product of arterial plasma concentration and RPF. The total arterial load of the infused amino acid, of course, is the sum of the arterial load, as calculated above, and the infused load. The renal venous load out is the product of the renal venous plasma concentration and the $\mathrm{RPF}$, corrected for both urine flow and rate of intra-arterial infusion of fluid. Glycine and glutamine were consistently extracted from plasma in net amounts, whereas alanine and serine were consistently produced and added to renal venous blood. The small net extraction of threonine is of insignificant magnitude and, on the basis of previous studies, is considered negligible and within limits of experimental error. ${ }^{1}$ These observations are in agreement with those of Shalhoub and associates $(8)$ and others $(5,12)$.

1 Plasma concentrations of aspartate are so low that they cannot be determined accurately. Production of glutamate was low, as previously described (8). Hence, neither amino acid is included in Table II.

TABLE I

Data obtained in a representative experiment in which amide-15 $N$-labeled glutamine was infused into the left renal artery of an acidotic dog*

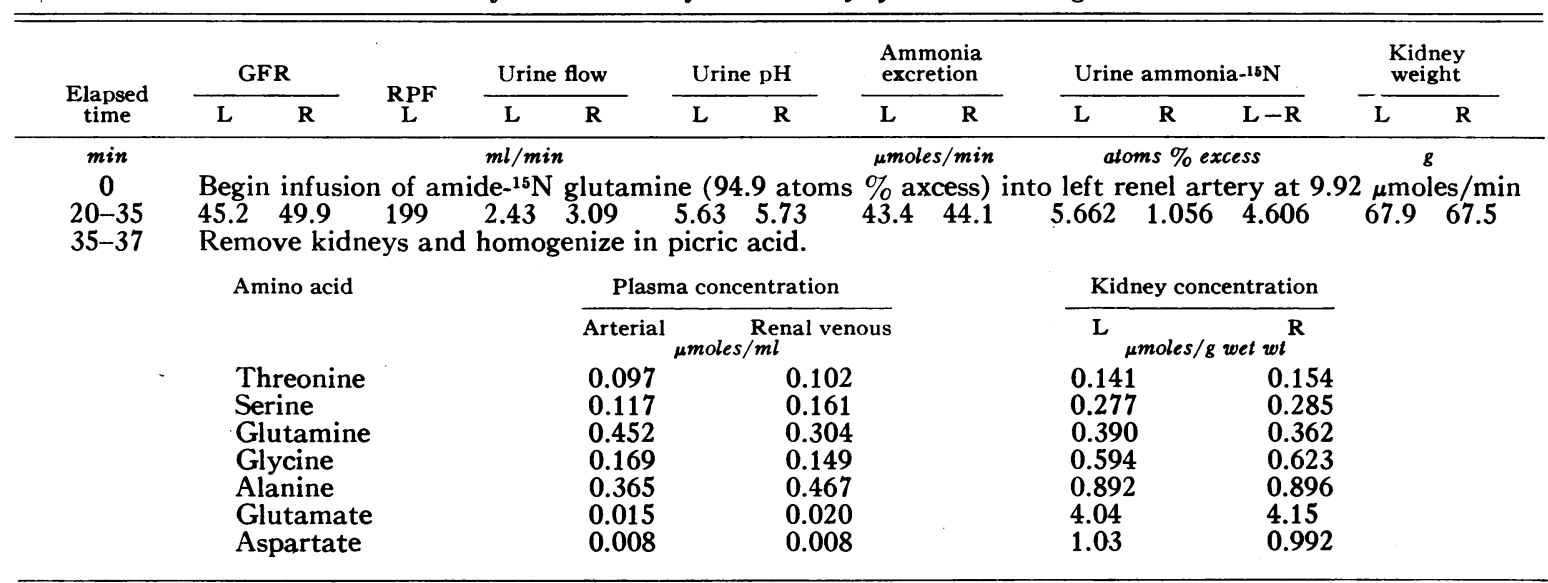

* Abbreviations: $\mathrm{GFR}=$ glomerular filtration rate, $\mathrm{RPF}=$ renal plasma flow, $\mathrm{L}=$ left, $\mathrm{R}=$ right. 
TABLE II

Summary of arteriovenous extractions of representative amino acids by the left kidney during the infusion of labeled compounds into the left renal artery

\begin{tabular}{|c|c|c|c|c|c|c|}
\hline \multirow{2}{*}{$\begin{array}{c}\text { Experi- } \\
\text { ment }\end{array}$} & \multirow[b]{2}{*}{ Compound infused } & \multicolumn{5}{|c|}{ Net extraction from plasma } \\
\hline & & Threonine & Serine & Glutamine & Glycine & Alanine \\
\hline & & & & $\mu \mathrm{moles} / \mathrm{min}$ & & \\
\hline $\begin{array}{l}1 \\
2\end{array}$ & Amino- ${ }^{15} \mathrm{~N}$ glutamine & $\begin{array}{l}-0.4 \\
-0.7\end{array}$ & $\begin{array}{l}-5.7 \\
-6.0\end{array}$ & $\begin{array}{l}+29.1 \\
+20.7\end{array}$ & $\begin{array}{l}+3.0 \\
+4.1\end{array}$ & $\begin{array}{l}-5.4 \\
-9.3\end{array}$ \\
\hline $\begin{array}{l}3 \\
4\end{array}$ & Ammonium chloride- ${ }^{15} \mathrm{~N}$ & $\begin{array}{l}-0.8 \\
-0.9\end{array}$ & $\begin{array}{l}-7.1 \\
-6.2\end{array}$ & $\begin{array}{l}+21.5 \\
+24.0\end{array}$ & $\begin{array}{l}+4.7 \\
+3.0\end{array}$ & $\begin{array}{l}-4.5 \\
-12.6\end{array}$ \\
\hline $\begin{array}{l}5 \\
6\end{array}$ & Amide-16 $\mathrm{N}$ glutamine & $\begin{array}{l}-0.9 \\
+0.5\end{array}$ & $\begin{array}{l}-8.5 \\
-5.1\end{array}$ & $\begin{array}{l}+39.9 \\
+28.9\end{array}$ & $\begin{array}{l}+4.2 \\
+3.8\end{array}$ & $\begin{array}{l}-19.7 \\
-10.9\end{array}$ \\
\hline \multirow[t]{2}{*}{$\begin{array}{l}7 \\
8\end{array}$} & Amino- ${ }^{15} \mathrm{~N}$ alanine & $\begin{array}{l}-0.2 \\
-0.4\end{array}$ & $\begin{array}{r}-8.8 \\
-10.2\end{array}$ & $\begin{array}{l}+42.4 \\
+34.9\end{array}$ & $\begin{array}{l}+4.9 \\
+6.2\end{array}$ & $\begin{array}{l}-13.8 \\
-13.1\end{array}$ \\
\hline & Mean & -0.5 & -7.2 & +30.2 & +4.2 & -11.2 \\
\hline
\end{tabular}

Table III summarizes the specific activities (atoms per cent excess ${ }^{15} \mathrm{~N}$ ) of left and right urinary ammonias and of the free tissue amino acids of left and right kidneys. Subtraction of the specific activity of the urinary ammonia or of a tissue amino acid of the noninfused kidney from the corresponding specific activity of urine or tissue of the infused kidney corrects for recirculation of label in any form. Corrected plasma specific activity is calculated by dividing the known rate of infusion of ${ }^{15} \mathrm{~N}$ by the total arterial load of that amino acid (perfused load + infused load, as described previously). Division of the specific activity of the compound measured in urine or in kidney (corrected for recirculation) by the plasma specific activity of the compound infused (similarly corrected for recirculation) gives the per cent of the product derived from the precursor.

Figure 1 demonstrates that ammonia nitrogen, presented to the kidney as preformed ammonia in the blood (A) or produced in the kidney from the amide nitrogen of plasma glutamine (B), is not significantly incorporated into the free aspartate, glutamate, glycine, or alanine of renal tissue. Thus, in the kidney of the acidotic dog, glutamate dehydrogenase does not catalyze the incorporation of significant amounts of labeled ammonia into glutamate.

It must be emphasized that the significance of the per cent of the urinary ammonia derived from blood ammonia is basically different from that of the per cent of the urinary ammonia derived from either nitrogen of plasma glutamine. Normally the concentration of arterial ammonia is very low (13-15). In our experiments the quantities of ${ }^{15} \mathrm{NH}_{4} \mathrm{Cl}$ infused are by no means tracer amounts relative to the normal arterial load of ammonia. Accordingly, the per cent of the urinary ammonia derived from the blood ammonia will, within limits, vary as a direct function of the rate of infusion of ${ }^{15} \mathrm{NH}_{4} \mathrm{Cl}$. The same is not true of experiments in which ${ }^{15} \mathrm{~N}$-labeled amino acids are infused and in which the infused load of the ${ }^{15} \mathrm{~N}$-labeled amino acid can be considered as a tracer quantity relative to the much larger normal perfused load of unlabeled amino acid.

Incorporation of label into amino acids is strikingly different when ${ }^{15} \mathrm{~N}$ is infused as amino-labeled glutamine or alanine, as shown by the experiments summarized in Figure 2, $A$ and $B$. Significant amounts of ${ }^{15} \mathrm{~N}$ are now incorporated into all of the free tissue amino acids studied. Presumably, such incorporation occurs by reactions involving transamination, certainly not by reductive amination of $\alpha$-ketoglutarate to form glutamate (see Figure 1, A and B).

Differences in per cent of ammonia, glutamate, aspartate, and so forth derived from a plasma precursor are related to each other in the same proportions as are the differences in the extent of their ${ }^{15} \mathrm{~N}$ labeling. This derives from the fact that the percentages, in any one experiment, are atoms per cent excess ${ }^{15} \mathrm{~N}$ of the several products factored by a common atoms per cent excess ${ }^{15} \mathrm{~N}$ of the precursor, times 100. It is evident from Figure 2, A, that the labeling of aspartate is greater than that of glutamate, an observation which indicates that the aspartate could not have been derived solely 
TABLE III

Incorporation of ${ }^{15} \mathrm{~N}$ into urinary ammonia and into representative free amino acids of renal tissue during the infusion of labeled compounds into the left renal artery

\begin{tabular}{|c|c|c|c|c|}
\hline \multirow{2}{*}{$\begin{array}{c}\text { Experi- } \\
\text { ment }\end{array}$} & \multirow[b]{2}{*}{ Compound analyzed } & \multicolumn{2}{|c|}{ Specific activity } & \multirow{2}{*}{$\begin{array}{c}\% \text { Derived } \\
\text { from inf used } \\
\text { compound }\end{array}$} \\
\hline & & $\mathbf{L}$ & $\mathbf{L}-\mathbf{R}$ & \\
\hline
\end{tabular}

atoms $\%{ }^{15} \mathrm{~N}$ excess

Amino- ${ }^{15} \mathrm{~N}$ glutamine (SA arterial plasma: exp. $1=14.6$, exp. $2=14.7$ atoms $\%$ excess)

$\begin{array}{llllll}1 & \text { Urinary ammonia } & 2.758 & 0.799 & 1.959 & 13.4 \\ 1 & & 2.623 & 1.025 & 1.598 & 10.9 \\ 2 & \text { Kidney aspartate } & 6.776 & 1.523 & 5.253 & 36.0 \\ 1 & & 6.585 & 1.871 & 4.714 & 32.1 \\ 2 & \text { Kidney glutamate } & 4.985 & 1.074 & 3.911 & 26.8 \\ 1 & & 4.370 & 1.370 & 3.000 & 20.4 \\ 2 & \text { Kidney alanine } & 4.614 & 1.365 & 3.249 & 22.3 \\ 1 & & 4.540 & 1.637 & 2.903 & 19.8 \\ 2 & \text { Kidney glycine } & 0.600 & 0.399 & 0.201 & 1.38 \\ & & 0.986 & 0.409 & 0.577 & 3.93\end{array}$

Ammonium chloride- ${ }^{16} \mathrm{~N}$ (SA arterial plasma: exp. $3=35.7$, exp. $4=28.7$ atoms $\%$ excess)

$\begin{array}{llcccc}3 & \text { Urinary ammonia } & 17.48 & 1.639 & 15.84 & 44.4 \\ 4 & & 14.92 & 0.940 & 13.98 & 48.8 \\ 3 & \text { Kidney aspartate } & 0.364 & 0.062 & 0.302 & 0.85 \\ 4 & & 0.389 & 0.065 & 0.324 & 1.13 \\ 3 & & 0.348 & 0.056 & 0.292 & 0.82 \\ 4 & \text { Kidney glutamate } & 0.296 & 0.124 & 0.172 & 0.60 \\ 3 & & & & 0.51 \\ 4 & \text { Kidney alanine } & 0.231 & 0.048 & 0.183 & 0.62 \\ 3 & & 0.270 & 0.093 & 0.177 & 0.03 \\ 4 & \text { Kidney glycine } & 0.015 & 0.004 & 0.011 & 0.06\end{array}$

Amide- ${ }^{16} \mathrm{~N}$ glutamine (SA arterial plasma: exp. $5=9.43$, exp. $6=8.80$ atoms $\%$ excess)

$\begin{array}{llllll}5 & \text { Urinary ammonia } & 5.662 & 1.056 & 4.606 & 48.9 \\ 6 & & 5.090 & 1.151 & 3.939 & 44.8 \\ 5 & \text { Kidney aspartate } & 0.087 & 0.037 & 0.050 & 0.53 \\ 6 & & 0.152 & 0.054 & 0.098 & 1.11 \\ 5 & & 0.083 & 0.075 & 0.008 & 0.09 \\ 6 & \text { Kidney glutamate } & 0.091 & 0.041 & 0.050 & 0.57 \\ 5 & & 0.122 & 0.034 & 0.088 & 0.93 \\ 6 & \text { Kidney alanine } & 0.105 & 0.056 & 0.049 & 0.56 \\ 5 & & 0.119 & 0.025 & 0.094 & 1.00 \\ 6 & \text { Kidney glycine } & 0.029 & 0.021 & 0.008 & 0.09\end{array}$

Amino- ${ }^{15} \mathrm{~N}$ alanine (SA arterial plasma: exp. $7=6.39 ;$ exp. $8=6.27$ atoms $\%$ excess)

\begin{tabular}{lllllc}
7 & Urinary ammonia & 0.504 & 0.197 & 0.307 & 4.80 \\
8 & & 0.503 & 0.167 & 0.336 & 5.36 \\
7 & & 1.036 & 0.481 & 0.555 & 8.69 \\
8 & Kidney aspartate & 1.646 & 0.413 & 1.233 & 19.7 \\
7 & & 0.868 & 0.288 & 0.580 & 9.08 \\
8 & Kidney glutamate & 1.182 & 0.292 & 0.890 & 14.2 \\
7 & & 3.853 & 1.054 & 2.799 & 43.8 \\
8 & Kidney alanine & 4.766 & 0.970 & 3.796 & 60.6 \\
7 & & 0.230 & 0.099 & 0.131 & 2.05 \\
8 & Kidney glycine & 0.294 & 0.107 & 0.187 & 2.98 \\
\hline
\end{tabular}




\section{${ }^{15} \mathrm{~N}$ AMMONIUM CHLORDE INFUSED}

\section{$15 \mathrm{~N}$ AMIDE GLUTAMINE INFUSED}
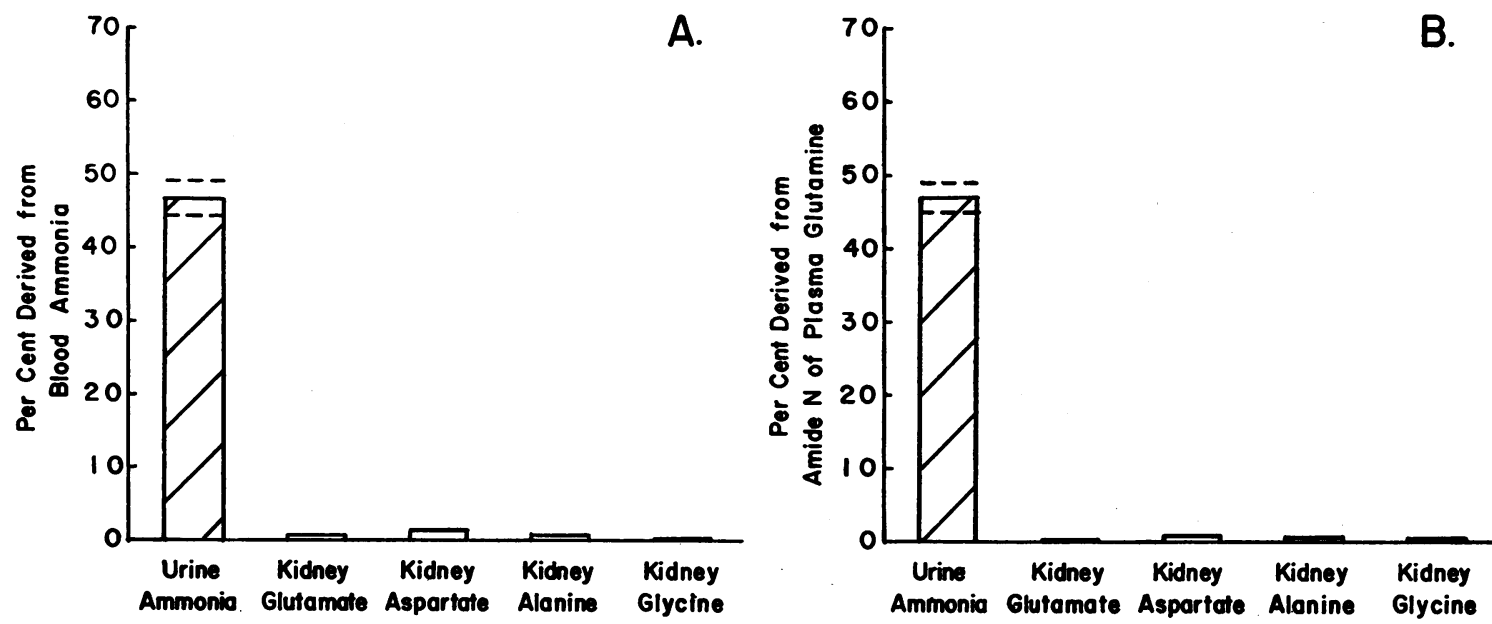

Fig. 1. Percentages of urinary ammonia and of free alanine, aspartate, glutamate and glycine of kidney TISSUE DERIVED FROM CIRCUlATING PLASMA PRECURSORS. A, percentages derived from blood ammonia. B, percentages derived from the amide nitrogen of glutamine. $\mathrm{A}$ and $\mathrm{B}$, each the mean of two experiments; ranges indicated by dashed lines.

from a uniformly labeled pool of glutamate. Thus, aspartate must be derived, at least in part, from a more highly labeled precursor.

It is apparent from Figure 2, B, that the alanine of kidney tissue becomes highly labeled when ${ }^{15} \mathrm{~N}$ alanine is infused into the renal artery. A mean of some $52 \%$ of kidney alanine had its origin from plasma alanine in these experiments;
$48 \%$ was derived from alanine synthesized de novo from unlabeled precursors by tubular cells.

It is also evident from Figure 2, $\mathrm{B}$, that glutamate could readily acquire its label from alanine by transamination of $\alpha$-ketoglutarate. Perhaps even the aspartate, which has a slightly higher label than glutamate, might be derived by transamination of oxalacetate by glutamate if one discounts

15N AMINO GLUTAMINE INFUSED

$15 \mathrm{~N}$ ALANINE INFUSED
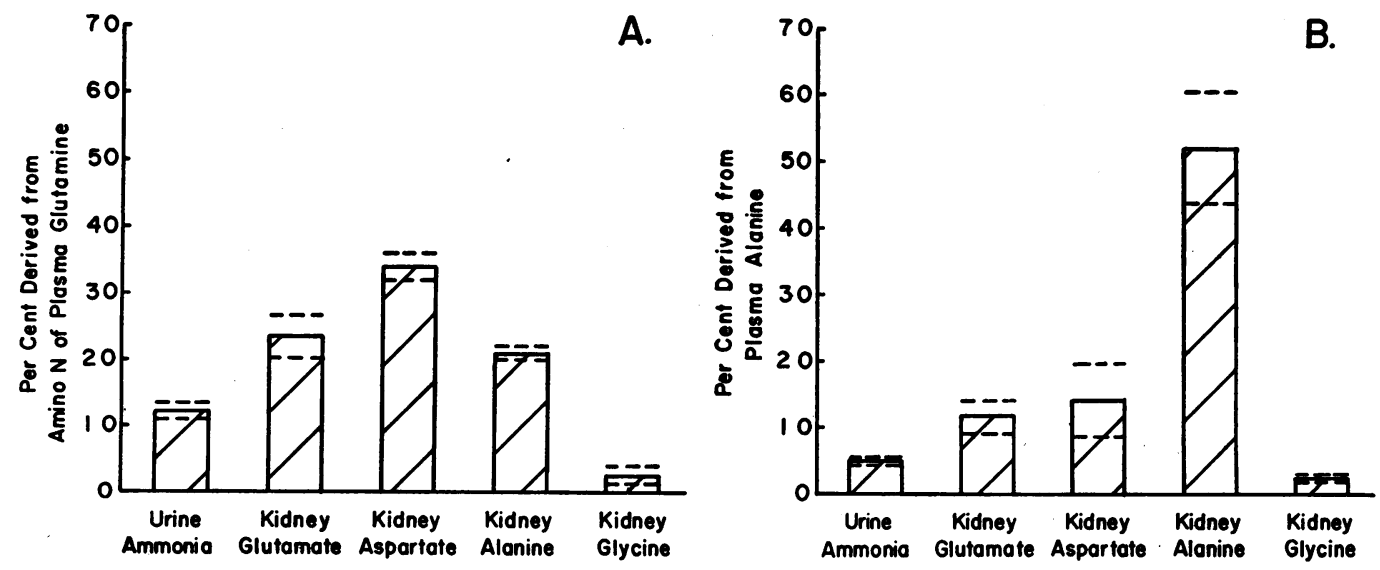

Fig. 2. Percentages of urinary ammonia and of free alanine, aspartate, glutamate, and glyCINE OF KIDNEY TISSUE DERIVED FROM CIRCULATING PLASMA PRECURSORS. A, percentages derived from amino nitrogen of glutamine. $B$, percentages derived from amino nitrogen of alanine. $A$ and $B$, each the mean of two experiments; ranges indicated by dashed lines. 
the small difference. In any event, the ammonia is probably derived from glutamate by oxidative deamination. Clearly, neither aspartate nor glutamate could acquire its label from tissue ammonia by reductive amination.

\section{Discussion}

Calculation of the per cent of a renal product derived from a precursor delivered to the kidney in arterial blood requires that a steady state exist. Thus, the specific activity of a precursor in renal tissue relative to its specific activity in plasma must be constant and independent of time. In all of our experiments, the labeled compound was infused into the renal artery at a constant rate for 20 minutes before the start of the clearance period. We inferred that a steady state was achieved during this time with respect to uptake and turnover of labeled precursor and formation of labeled product. Steady state conditions very probably existed in experiments in which glutamine was infused and demonstrably existed in experiments in which alanine and ammonia were infused.

Pitts, Pilkington, and De Haas (4) observed that the time for attainment of constancy of labeling of urinary ammonia after starting an intraarterial infusion of amide-labeled glutamine is less than 5 minutes. This fact, coupled with the small intrarenal pool of glutamine and high rate of extraction of glutamine from plasma (8), indicates that the glutamine pool of the kidney turns over rapidly. Since essentially no glutamine is synthesized by the dog kidney (16), it follows that the atoms per cent excess ${ }^{15} \mathrm{~N}$ of renal glutamine must become equal to the atoms per cent excess ${ }^{15} \mathrm{~N}$ of plasma glutamine within less than $5 \mathrm{~min}$ utes. The fact that we have been unable to isolate glutamine from renal tissue in pure form in amounts sufficient for accurate ${ }^{15} \mathrm{~N}$ analysis has prevented a direct test of this thesis.

Such a test is possible for alanine, and its basis is illustrated in Figure 3. The situation is complicated by the fact that alanine is synthesized within the kidney in amounts approximating those filtered and reabsorbed. In the experiment summarized in Figure 3, the perfused load of alanine was $93.8 \mu$ moles per minute (product of plasma alanine concentration and RPF). Seven $\mu$ moles per minute of alanine containing $6.32 \mu$ moles ${ }^{15} \mathrm{~N}$ excess was infused into the renal artery. Cor-

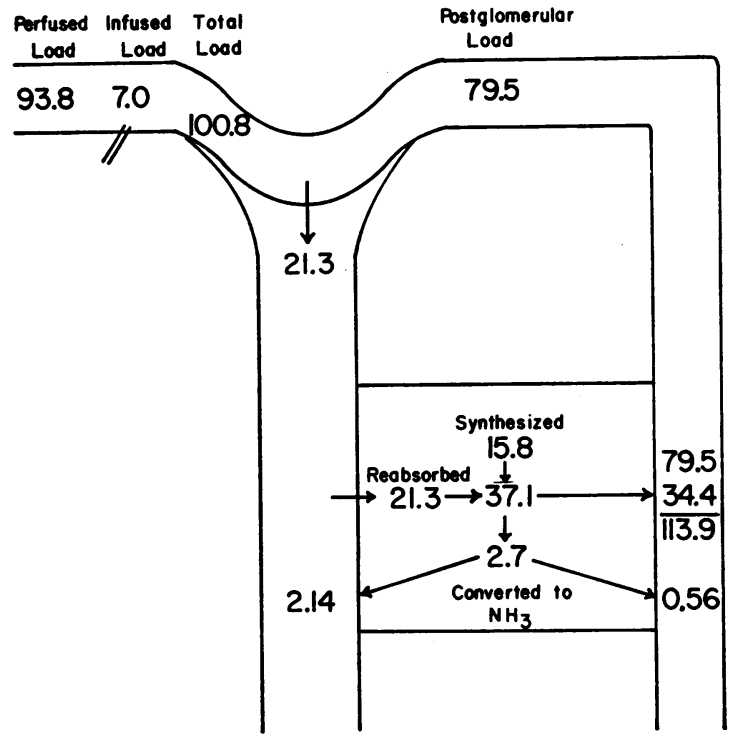

Fig. 3. Renal balance of alanine, illustrating THE CONTRIBUTIONS OF FILTERED AND REABSORBED ALANINE TO THE TOTAL RENAL POOL.

rected specific activity of the total arterial load was thus $6.32 / 100.8 \times 100=6.27$ atoms $\%$ excess. The filtered load of alanine was $21.3 \mu$ moles per minute (product of GFR and plasma alanine concentration). Obviously, the filtered alanine must have had the same specific activity as the plasma alanine. Since all was reabsorbed, $21.3 \mu$ moles of alanine, which had the same specific activity as plasma, entered tubular cells from the lumen each minute. Reabsorbed alanine- ${ }^{15} \mathrm{~N}$ therefore amounted to $1.336 \mu$ moles excess $(21.3 \mu$ moles $X$ 6.27 atoms $\%$ excess/100). Alanine was synthesized $^{2}$ from unlabeled nitrogen sources and added to the renal pool at a rate of $15.8 \mu$ moles per minute. The pool turned over at a rate of $37.1 \mu$ moles per minute $(21.3+15.8)$. Dividing ${ }^{15} \mathrm{~N}$ alanine added to the renal pool each minute (1.336 $\mu$ moles) by rate of turnover of the pool (37.1 $\mu$ moles) and multiplying by 100 gives an apparent specific activity of renal alanine of 3.60 atoms $\%$ ${ }^{15} \mathrm{~N}$ excess. The measured specific activity of renal alanine was 3.796 atoms $\%{ }^{15} \mathrm{~N}$ excess, a

2 The rate of synthesis of alanine is a calculated minimal one. It is derived from the measured net positive extraction of alanine $(113.9-100.8=13.1 \mu$ moles per minute) plus the measured conversion of alanine to urinary ammonia (2.14 $\mu$ moles per minute) plus the estimated contribution of alanine to the ammonia added to renal venous blood ( $0.56 \mu$ moles per minute). 
value $105 \%$ of the predicted one. Therefore, after 20 minutes of intra-arterial infusion a steady state has been attained, such that the ${ }^{15} \mathrm{~N}$ of the alanine of the renal pool has become a constant fraction of the ${ }^{15} \mathrm{~N}$ of the alanine of arterial plasma. These calculations also indicate that alanine enters tubular cells only through their luminal surfaces as a consequence of filtration and reabsorption. Equilibration of tissue alanine with alanine of peritubular capillary blood does not occur to any appreciable extent.

Renal ammonia, like renal alanine, is a mixture of that taken up by tubular cells from blood and that synthesized within tubular cells from a variety of precursors. Our evidence (17) indicates that ${ }^{15} \mathrm{NH}_{4} \mathrm{Cl}$ infused into a renal artery distributes throughout a well-mixed pool, which includes not only tubular cells but also tubular urine and peritubular blood, all phases having a common specific activity. This provides substance for the expressed view that the free base is in diffusion equilibrium among all phases of the renal cortex $(14,18)$.

In Figures 1 and 2, percentages of urinary ammonia derived from given precursors are compared with percentages of tissue amino acids derived from those same precursors. For the reasons stated above one could equally well designate the bar marked urinary ammonia as tissue ammonia.

Figure 1 demonstrates that, in the acidotic dog, the glutamate dehydrogenase reaction, glutamate $+\mathrm{NAD}^{+} \rightleftharpoons \alpha$-ketoglutarate $+\mathrm{NH}_{3}+\mathrm{NADH}+$ $\mathrm{H}^{+}$, although reversible, does not proceed appreciably in the direction of glutamate synthesis. The production of ammonia and $\alpha$-ketoglutarate from glutamate presumably is favored by a high ratio of $\mathrm{NAD}^{+}$to $\mathrm{NADH}$, the removal in urine or blood of the ammonia formed in the reaction, a high concentration of tissue glutamate relative to $\alpha$-ketoglutarate, or unknown factors. The above findings do not mean that the acidotic kidney does not form glutamate from $\alpha$-ketoglutarate, only that the glutamate dehydrogenase pathway is of minor significance. Our evidence (19) shows that the label of $\alpha$-ketoglutarate- $-{ }^{-14} \mathrm{C}$ is rapidly incorporated into renal glutamate, presumably through transamination by a number of amino acids, which ultimately yield their amino nitrogen as ammonia $(20,21)$.
Figure 2, A, demonstrates that the ${ }^{15} \mathrm{~N}$ of aminolabeled glutamine appears in the urinary ammonia and in tissue glutamate, aspartate, alanine, and glycine. The extent of the labeling of tissue aspartate very significantly exceeds that of tissue glutamate. Therefore, the aspartate pool of renal tissue could not have acquired its label from a common pool of glutamate labeled only to the degree shown in Figure 2, A. It must have acquired its ${ }^{15} \mathrm{~N}$ from a precursor more highly labeled than this common pool. Two possibilities are evident. 1) The aspartate could acquire its label, at least in part, from plasma and tissue glutamine by direct transamination of oxalacetate by the glutaminase II reaction. Glutamine + oxalacetate $\rightarrow$ aspartate $+\alpha$-ketoglutaramate; $\alpha$-ketoglutaramate $\rightarrow \alpha$-ketoglutarate $+\mathrm{NH}_{3}$. 2) The aspartate could acquire its label as a consequence of conventional transamination of oxalacetate by a compartmented highly labeled pool of glutamate. Oxalacetate + glutamate $\rightleftharpoons$ aspartate $+\alpha$-ketoglutarate. The highly labeled glutamate could represent a small intramitochondrial pool of glutamate formed from glutamine by the glutaminase 1 reaction and not yet transferred to the lesser labeled cytoplasmic pool.

From Figure 2, A, it would appear that tissue alanine could have acquired its label from the common pool of glutamate by transamination of pyruvate. Actually it could not, for the renal pool of alanine is a mixture of unlabeled, filtered, and reabsorbed alanine plus newly synthesized alanine, which derived its label ultimately from the amino nitrogen of tissue glutamine. Highly labeled synthesized alanine plus unlabeled, filtered, and reabsorbed alanine constitute the mixture analyzed as tissue alanine. From the calculations presented in the first part of the discussion, it is evident that the newly synthesized alanine must have had a specific activity more than twice that of the mixed renal pool.

We have no data that establish either of the two explanations cited above for the high labeling of alanine and aspartate relative to glutamate. In rat liver, glutaminase $I$ is a mitochondrial enzyme (22). Therefore, glutamate formed by the deamination of glutamine must be compartmented to some extent within mitochondria. However, the bulk of the glutamate-pyruvate transaminase of rat liver is extramitochondrial in locus (23). 
Hence, highly labeled glutamate might have to enter the less labeled cytoplasmic pool to transaminate pyruvate effectively. The alanine label would approach that of the common pool of glutamate. In contrast, the pyruvate-activated glutaminase II of rat liver is entirely cytoplasmic (22). Direct transamination of pyruvate by cytoplasmic glutamine could form highly labeled alanine. This argument is not conclusive, for the intracellular loci of enzymes in the dog kidney are not known and may differ from those of rat liver. Furthermore, in rat liver the bulk of the glutamateoxalacetate transaminase is contained within mitochondria (24). Additionally, studies on partially purified glutamine transaminase of rat liver have demonstrated only minor direct transfer of the amino nitrogen of glutamine to oxalacetate (25). No studies on transfer activities of the enzyme of dog kidney are available, but they may differ from those of rat liver. Richterich and Goldstein (26) and Pollak, Mattenheimer, DeBruin, and Weinman (27) have observed that the kidney of the dog contains active glutamine transaminase and glutaminase. Our data suggests that glutamine transaminase may play a significant role in the synthesis of ammonia, aspartate, and alanine but do not prove it.

Figure 2, B, shows that $52 \%$ of kidney alanine is derived from plasma alanine and $48 \%$ is synthesized within the kidney. This latter moiety acquires its nitrogen in large part from the amino group of glutamine. Obviously, in these experiments, glutamate could derive its label by transamination of $\alpha$-ketoglutarate by tissue alanine. Labeled glutamate could, in turn, account for the label that appears in urinary ammonia by way of the glutamate dehydrogenase pathway. Aspartate and glutamate are labeled to approximately the same extent. Hence, aspartate might be formed from oxalacetate by transamination with glutamate, the commonly inferred final step in the sequence of alanine to glutamate to aspartate. If, however, the labeling of aspartate significantly exceeds that of glutamate, a more direct transfer from a more highly labeled source would be indicated, as discussed above.

Glycine is not labeled to an appreciable extent by any of the ${ }^{15} \mathrm{~N}$-labeled compounds infused, a fact which supports the observation that glycine of plasma plays only a minor role in renal ammonia formation (4). Thus, glycine appears to be neither a major plasma precursor nor a major tissue intermediate of the ammonia produced by the kidney.

\section{References}

1. Blanchard, M., D. E. Green, V. Nocito, and S. Ratner. L-Amino acid oxidase of animal tissue. J. biol. Chem. 1944, 155, 421.

2. Archibald, R. M. Chemical characteristics and physiological roles of glutamine. Chem. Rev. 1945, 37, 161.

3. White, A., P. Handler, and E. L. Smith. Principles of Biochemistry, 3rd ed. New York, McGrawHill, 1964, p. 488.

4. Pitts, R. F., L. A. Pilkington, and J. C. M. De Haas. ${ }^{15} \mathrm{~N}$ tracer studies on the origin of urinary ammonia in the acidotic dog, with notes on the enzymatic synthesis of labeled glutamic acid and glutamines. J. clin. Invest. 1965, 44, 731.

5. Pitts, R. F., and W. J. Stone. Renal metabolism of alanine. J. clin. Invest. 1967, 46, 530.

6. Pilkington, L. A., R. Binder, J. C. M. De Haas, and R. F. Pitts. Intrarenal distribution of blood flow. Amer. J. Physiol. 1965, 208, 1107.

7. Wolf, A. V. Total renal blood flow at any urine flow or extraction fraction (abstract). Amer. J. Physiol. 1941, 133, 496.

8. Shalhoub, R., W. Webber, S. Glabman, M. CanessaFischer, J. Klein, J. DeHaas, and R. F. Pitts. Extraction of amino acids from and their addition to renal blood plasma. Amer. J. Physiol. 1963, 204, 181.

9. Tallan, H. H., S. Moore, and W. H. Stein. Studies on the free amino acids and related compounds in the tissues of the cat. J. biol. Chem. 1954, 211, 927.

10. Hirs, C. H. W., S. Moore, and W. H. Stein. The chromatography of amino acids on ion exchange resins. Use of volatile acids for elution. J. Amer. chem. Soc. 1954, 76, 6063.

11. Wilson, D. W., A. O. C. Nier, and S. P. Reimann. Preparation and Measurement of Isotopic Tracers. Ann Arbor, J. W. Edwards, 1964, p. 34.

12. Owen, E. E., and R. R. Robinson. Amino acid extraction and ammonia metabolism by the human kidney during the prolonged administration of ammonium chloride. J. clin. Invest. 1963, 42, 263.

13. Nash, T. P., Jr., and S. R. Benedict. The ammonia content of the blood, and its bearing on the mechanism of acid neutralization in the animal organism. J. biol. Chem. 1921, 48, 463.

14. Denis, G., H. Preuss, and R. Pitts. The $\mathrm{pNH}_{3}$ of renal tubular cells. J. clin. Invest. 1964, 43, 571.

15. Pilkington, L. A., J. Welch, and R. F. Pitts. Relationships of $\mathrm{pNH}_{3}$ of tubular cells to renal production of ammonia. Amer. J. Physiol. 1965, 208, 1100 . 
16. Krebs, H. A. Metabolism of amino-acids. IV. The synthesis of glutamine from glutamic acid and ammonia, and the enzymic hydrolysis of glutamine in animal tissues. Biochem. J. 1935, 29, 1951.

17. Stone, W. J., S. Balagura, and R. F. Pitts. Unpublished data.

18. Pitts, R. F. Renal production and excretion of ammonia. Amer. J. Med. 1964, 36, 720.

19. Lyon, M. L., and R. F. Pitts. Unpublished data.

20. Lotspeich, W. D., and R. F. Pitts. The role of amino acids in the renal tubular secretion of ammonia. J. biol. Chem. 1947, 168, 611.

21. Kamin, H., and P. Handler. The metabolism of parenterally administered amino acids. III. Ammonia formation. J. biol. Chem. 1951, 193, 873.

22. De Duve, C., R. Wattiaux, and P. Baudhuin. Distribution of enzymes between subcellular fractions in animal tissues. Advanc. Enzymol. 1962, 24, 291.
23. Kafer, E., and J. K. Pollak. Amino acid metabolism of growing tissues. II. Alanine-glutamic acid transaminase activity of embryonic rat liver. Exp. Cell Res. 1961, 22, 120.

24. Eichel, H. J., and J. Bukovsky. Intracellular distribution pattern of rat liver glutamic-oxalacetic transaminase. Nature (Lond.) 1961, 191, 243.

25. Meister, A., and S. V. Tice. Transamination from glutamine to $\alpha$-keto acids. J. biol. Chem. 1950, $187,173$.

26. Richterich, R. W., and L. Goldstein. Distribution of glutamine metabolizing enzymes and production of urinary ammonia in the mammalian kidney. Amer. J. Physiol. 1958, 195, 316.

27. Pollak, V. E., H. Mattenheimer, H. DeBruin, and K. J. Weinman. Experimental metabolic acidosis: the enzymatic basis of ammonia production by the dog kidney. J. clin. Invest. 1965, 44, 169.

\section{NOTICE TO SUBSCRIBERS}

Post Offices will not forward the Journal when you move.

Please notify The Journal of Clinical Investigation, The Rockefeller University Press, Box 261, New York, N. Y. 10021, when your address changes. Include your zip code number. 